\title{
Pengaruh Inventory Turnover, Sales Growth, dan Liquidity Terhadap Profitabilitas pada PT. Sumber Alfaria Trijaya, Tbk Tanjung Morawa Periode 2013-2017
}

\author{
Keumala Hayati \\ Universitas Prima Indonesia \\ Medan \\ keumalahayatihakim@gmail.com
}

Renita Ferawati Lumban Gaol Universitas Prima Indonesia Medan

renitaferawatigaol@gmail.com

\author{
Antonius KAP Simbolon \\ Universitas Prima Indonesia \\ Medan \\ antoniussimbolon8@gmail.com
}

Intan Permata Sari Sianturi

Universitas Prima Indonesia Medan

Intanpermatasianturi@gmail.com

\author{
Yosua Michael Sagala \\ Universitas Prima Indonesia \\ Medan \\ Yosuamichael02@gmail.com
}

\begin{abstract}
ABSTRAK
This research aims to exsplain the effect Inventory Turnover, Sales Growth, and Liquidity on Profitability. This study was conducted at PT Sumber Alfaria Trijaya Tbk Tanjung Morawa in periods of 2013-2017 with a total study population of 60 months. The sampling technique used in this study is sampling jenuh and acquired 60 months samples. The analisys technique used is multiple linear regressions, both $t$ test and $F$ test. The dependent variable is profitability while the independent variable is Inventory Turnover, Sales Growth, and Liquidity
\end{abstract}

Keywords : Inventory Turnover, Sales Growth, Liquidity and profitability

\section{Pendahuluan}

PT. Sumber Alfaria Trijaya, Tbk Tanjung Morawa adalah salah satu perusahaan terbesar di indonesia yang telah didirikan sejak tahun 2012 yang bergerak di bidang perdagangan dan distribusi yang memasuki sektor ritel minimarket di indonesia yang menyediakan barang-barang kebutuhan pokok dengan harga yang terjangkau, tempat belanja yang nyaman serta lokasi yang mudah dijangkau. Alasan memilih PT. Sumber Alfaria Trijaya,Tbk Tanjung Morawa karena di indonesia pertumbuhan toko atau minimarket semakin pesat. Maka dari itu, perusahaan dituntut untuk melakukan inovasi dan pengembangan serta menerapkan standarisasi dan pengoperasian yang jelas.

\section{Studi Literatur}

Masyarakat tidak lepas dari barang-barang keperluan sehari-hari seperti barang-barang konsumsi dan barang industri lainnya yang dibutuhkan setiap harinya. Hal ini akan memacu perusahaan PT. Sumber Alfaria Trijaya, Tbk Tanjung Morawa akan meningkatkan produksinya sehingga pertumbuhan perusahaan setiap tahunnya akan terus meningkat dan dapat bersaing dengan perusahaan lainnya.

Adapun fenomena yang menggambarkan Pengaruh dari Perputaran Persediaan, Pertumbuhan Penjualan dan Likuiditas 
terhadap Profitabilitas yang terjadi pada PT. Sumber Alfaria Trijaya, Tbk Tanjung Morawa

dapat dilihat pada tabel sebagai berikut

Tabel I Fenomena Inventory Turnover, Sales Growth, and Liquidity PT. Sumber Alfaria Trijaya, Tbk Tanjung Morawa Periode 2013-2017

\begin{tabular}{|l|l|l|l|l|l|}
\hline Tahun & Bulan & Persediaan & Penjualan & Aktiva lancar & Laba \\
\hline \multirow{3}{*}{2015} & Juni & 146.746 .343 .556 & 100.253 .356 .081 & 251.469 .764 .067 & 116.523 .749 .669 \\
\cline { 2 - 6 } & Juli & 134.914 .522 .275 & 110.812 .598 .485 & 251.773 .919 .452 & 119.391 .651 .151 \\
\cline { 2 - 6 } & Agustus & 123.219 .679 .110 & 97.000 .068 .190 & 268.777 .371 .363 & 123.179 .134 .328 \\
\hline \multirow{3}{*}{2016} & Juni & 186.514 .478 .301 & 94.696 .681 .898 & 273.862 .623 .588 & 198.298 .027 .427 \\
\cline { 2 - 6 } & Juli & 160.458 .401 .046 & 104.977 .281 .934 & 244.293 .445 .728 & 205.437 .183 .878 \\
\cline { 2 - 6 } & Agustus & 155.166 .852 .534 & 88.093 .339 .033 & 230.525 .620 .049 & 214.984 .631 .785 \\
\hline \multirow{3}{*}{2017} & Juni & 222.520 .387 .692 & 131.004 .630 .178 & 319.692 .513 .351 & 309.103 .067 .193 \\
\cline { 2 - 6 } & Juli & 198.595 .619 .432 & 115.726 .834 .952 & 286.257 .212 .321 & 318.034 .502 .173 \\
\cline { 2 - 6 } & Agustus & 203.732 .924 .171 & 106.483 .901 .059 & 283.439 .463 .577 & 327.881 .190 .131 \\
\hline
\end{tabular}

Sumber : PT. Sumber Alfaria Trijaya, Tbk Tanjung Morawa

Pada tabel 1 menunjukkan bahwa fenomena yang terjadi pada PT. Sumber Alfaria Trijaya, Tbk Tanjung Morawa fenomena terjadi pada bulan juli-agustus 2015 menunjukkan persediaan mengalami penurunan sebesar 0,08 $\%$ sedangkan laba mengalami kenaikan sebesar 0,03\%. Pada tahun 2016 terjadi fenomena pada bulan juli-agustus dimana penjualan mengalami penurunan sebesar $0,16 \%$ sedangkan laba naik sebesar $0,04 \%$. Dan fenomena juga terjadi pada tahun 2017 dimana aktiva lancar mengalami penurunan sebesr $0,09 \%$ sedangkan laba nya naik sebesar $0,03 \%$.

Adapun identifikasi masalah dalam penelitian ini adalah.

1. Kenaikan Inventory Turnover tidak selalu di ikuti oleh kenaikan Profitabilitas pada PT. Sumber Alfaria Trijaya, Tbk Tanjung Morawa

2. Kenaikan Sales Growth tidak selalu di ikuti oleh kenaikan Profitabilitas pada PT. Sumber Alfaria Trijaya, Tbk Tanjung Morawa

3. Kenaikan Liquidity tidak selalu di ikuti oleh kenaikan Profitabilitas pada PT. Sumber Alfaria Trijaya, Tbk Tanjung Morawa

4. Kenaikan Inventory Turnover, Sales Growth dan Liquidity tidak selalu di ikuti oleh kenaikan profitabilitas pada PT. Sumber Alfaria Trijaya Tanjung Morawa Berdasarkan tabel fenomena diatas dapat dirumuskan adalah seberapa besar pengaruh Inventory Turnover, Sales Growth dan Liquidity terhadap profitabilitas pada PT. Sumber Alfaria Trijaya, Tbk Tanjung Morawa periode 2013-2017?

Hasil penelitian ini diharapkan bermanfaat bagi peneliti, dan peneliti selanjutnya untuk memperluas wawasan dan menambah pengetahuan tentang Inventory Turnover, Sales Growth, Liquidity dan Profitabilitas. Penelitian ini juga berfungsi bagi para investor dalam pengambilan keputusan saat berinvestasi.

Inventory Turnover adalah rasio yang mengukur berapa besar tingkat kemampuan perusahaan dalam mengelola barang yang akan dijual selama satu periode.

Menurut Raharjaputra (2009 : 204) Inventory Turnover semakin tinggi inventory turn over maka akan semakin tinggi keuntungan yang diperoleh.

\section{Perputaran Persediaan $=$ Beban Pokok Penjualan Pesediaan Rata-rata}

Adapun manfaat dari Inventory Turnover 
Menurut Kasmir (2012:174) adalah untuk mengetahui rata-rata sediaan tersimpan dalam gudang, dan berapa kali persediaan tersebut terjual dalam satu periode.

Penelitian yang pernah di lakukan oleh Hayati (2016) penelitian ini menyimpulkan bahwa perputaran persediaan berpengaruh negatif terhadap profitabilitas.

Sales Growth merupakan hal yang paling penting bagi suatu perusahaan dimana sales growth adalah komponen utama penghasilan perusahaan, setiap perusahaan pasti akan berupaya untuk meningkatkan penjualan produknya. Sales growth juga menggambarkan kemampuan perusahaan dalam mempertahankan posisi ekonominya di tengah pertumbuhan dalam sektor usahanya Kasmir (2012 : 114)

Adapun rumus untuk menghitung sales growth adalah :

Pertumbuhan Penjualan $=$

$$
\frac{\text { Jual Tahun ini- Jual (T-1) }}{\text { Penjualan (T-1) }}
$$

Adapun manfaat dan tujuan pada sektor penjualannya adalah sebagai berikut :

1. Untuk mengetahui berapa kali dana yang ditanamkan dalam aktivitas agar tetap berputar dalam satu periode.

2. Untuk mengetahui penggunaan semua aktiva perusahaan dibandingkan dengan penjualan dalam satu periode tertentu.

Liquidity ratio adalah kemampuan perusahaan untuk membayar kewajibankewajibannya yang segera harus dipenuhi, (Sutrisno 2012:222)

Menurut Hantono dan Hwee (2017 : 132) sebagaimana aktiva lancar memenuhi kwajiban kewajiban lancar.

Menurut Hayati (2016) Rasio ini digunakan untuk mengukur kemampuan perusahaan untuk membayar kewajiban yang segera jatuh tempo

Rumus untuk menghitung liquidity adalah : Current Ratio =

Current Assets (Aktiva Lancar)

Current Liabilities (Utang Lancar)

Penelitian yang pernah dilakukan oleh
Hayati (2016) penelitian ini menyimpulkan bahwa Liquidity berpengaruh positif terhadap profitabilitas.

Manfaat dari liquidity adalah untuk mengukur kemampuan perusahaan membayar kewajiban, mengukur kemampuan perusahaan membayar kewajiban jangka pendek dengan aktiva lancar secara keseluruhan dan untuk mengukur seberapa besar uang kas yang tersedia untuk membayar utang.

\section{Rasio profitabilitas dengan menggunakan ( Return on Assets)}

Rasio profitabilitas, rasio ini menggambarkan kemampuan perusahaan untuk menghasilkan keuntungan Muhadi (2013:63). Profitabilitas juga disebut sebagai rentabilitas dimana kemampuan perusahaan mendapatkan laba seperti kegiatan penjulan, kas, modal, jumlah karyawan, jumlah cabang dan lain-lain.

\section{Return on Asset $=\underline{\text { Penjualan Bersih }}$ Total Aktiva}

Kerangka konseptual dapat digambarkan sebagai berikut :

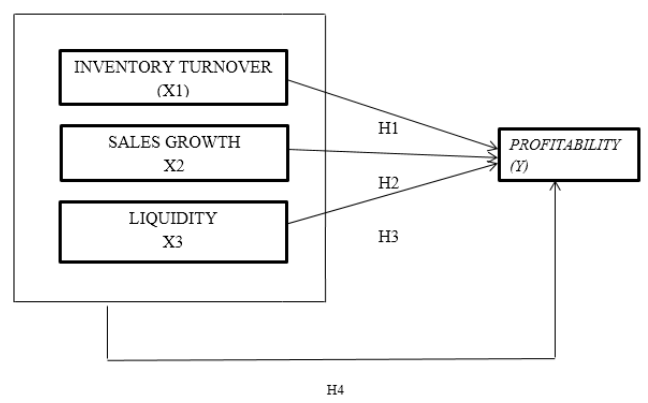

Dari tabel kerangka konseptual tersebut maka hipotesis penelitian ini adalah :

Inventory Turnover, Sales Growth dan Liquidity berpengaruh secara partial terhadap profitabilitas pada PT. Sumber Alfaria Trijaya, Tbk Tanjung Morawa periode tahun 2013-2017. Inventory Turnover, Sales Growth dan Liquidity berpengaruh secara simultan terhadap profitabilitas pada PT. Sumber Alfaria Trijaya, Tbk Tanjung Morawa periode 2013-2017.

\section{Metodologi Penelitian}

Jenis dan sumber data jenis data yang 
digunakan dalam penelitian ini adalah data primer, sumber data langsung yang diambil langsung oleh pengumpul data. Sumber data diperoleh dari laporan keuangan pada tahun 2013-2017 melalui perusahaan PT. Sumber Alfaria Trijaya, Tbk Tanjung Morawa.

Populasi dan sampel Populasi yang digunakan yaitu pada perusahaan PT. Sumber Alfaria Trijaya, Tbk Tanjung Morawa. dengan sampel sebanyak 60, dengan teknik pengumpulan sampel yaitu sampling jenuh, yaitu seluruh anggota populasi digunakan sebagai sampel.

Identifikasi dan defenisi operasional variabel penelitian variabel independen sama dengan variabel bebas yang artinya variabel yang menjadi pengaruh atau yang menjadi sebab perubahannya .

Variabel dependen atau disebut juga variabel terikat yang artinya variabel yang dipengaruhi atau yang menjadi akibat.

\section{Hasil Penelitian}

Metode Analisis penelitian ini menggunakan pendekatan dengan metode kuantitatif. Jenis penelitian ini adalah menggunakan deskriptif. Dalam penelitian ini, metode analisis data yang digunakan adalah metode analisis statistik dengan menggunakan software SPSS 23. Untuk pengujian hipotesis dilakukan analisis regresi linear berganda model regresi yang digunakan adalah sebagai berikut.

$$
\mathrm{Y}=\mathrm{a}+\mathrm{b}_{1} \mathrm{X}_{1}+\mathrm{b}_{2} \mathrm{X}_{2}+\mathrm{b}_{3} \mathrm{X}_{3}+\mathrm{e}
$$

Keterangan :

$\mathrm{Y}=$ Profitabilitas

A $=$ Konstanta

b1= Koefisien regresi variabel X1 (Inventory

Turnover

b2 = Koefisien regresi variabel X2 (Sales

Growth)

b3= Koefisien regresi variabel X3 (Liquidity)

$\mathrm{X} 1=$ Variabel Inventory Turnover

$\mathrm{X} 2=$ Variabel Sales Growth

X3= Variabel Liquidity

$\mathrm{E}=$ Persentase Kesalahan $(0,05)$

Pengujian asumsi klasik yang dilakukan terdiri atas uji normalitas, uji multikolineritas, uji heterokedasitas, dan uji autokorelasi. Hasil pengujian asumsi klasik ini menggunakan software SPSS 23.

\subsection{Hasil Analisis}

\section{Uji Normalitas}

ada dua cara untuk mendeteksi uji normalitas dengan analisis statistic dan analisis grafik

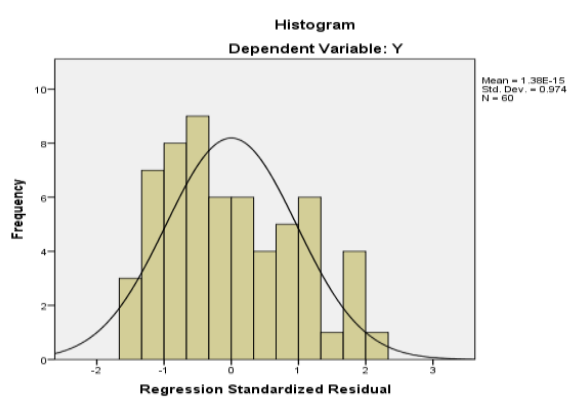

Untuk melihat normalitas residual adalah dengan melihat grafik histogram, pada grafik diatas garis mendekati diagonal maka tabel tersebut dikatakan normal. Grafik histogram adalah grafik yang membandingkan antara data observasi dengan distribusi yang mendekati distribusi normal.

2. Multikolinearitas

\section{Coefficients $^{\mathrm{a}}$}

\begin{tabular}{|l|l|l|l|l|}
\hline \multicolumn{2}{|l|}{} & \multicolumn{2}{l|}{$\begin{array}{l}\text { Collinearity } \\
\text { Statistics }\end{array}$} \\
\hline $\begin{array}{l}\text { Zero- } \\
\text { order }\end{array}$ & Partial & Part & Tolerance & VIF \\
\hline & & & & \\
\hline .043 & .315 & .272 & .784 & 1.275 \\
.485 & .559 & .552 & .885 & 1.130 \\
-.124 & -.269 & - & .866 & 1.155 \\
\hline
\end{tabular}

Nilai tolerance variabel Inventory Turnover, Sales Growth dan Liquidity berada diatas 0,1 sedangkan nilai VIF variabel. Inventory Turnover, Sales Growth dan Liquiditydi bawah 0. Dengan demikian hasil uji multikolinearitas dapat disimpulkan tidak 
terjadi kolerasi antar variabel independen.

3. Autokorelasi

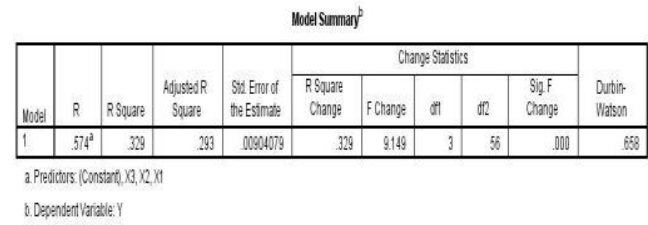

Dalam uji Autokolerasi dengan menggunakan uji Durbin-Watson mengahasilkan nilai statistik sebesar (DW) $=0,658$ dimana pada penelitian ini jumlah sampel 60 dan variabel independen sebanyak 3. Dari jumlah tersebut maka dihasilkan $\mathrm{dL}=1,479$ dan $\mathrm{dU}=1,688$. Dw terletak antara Du dan (4-dU)= $1,688>0,658<2,312$ maka disimpulkan tidak terjadi autokolerasi.

\section{Heteroskedastisitas}

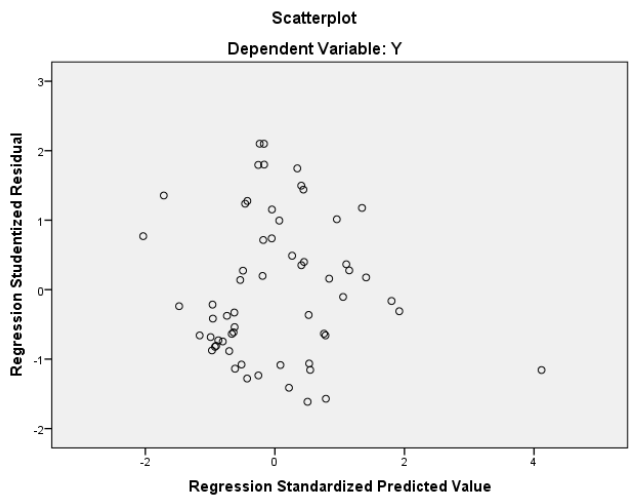

Hasil uji heteroskedastisitas dapat dilihat bahwa titik-titik menyebar secara acak serta tersebar baik di atas maupun di bawah angka 0 pada sumbu $\mathrm{Y}$.

\section{Model Regresi \\ Uji Statistik t}

untuk mengetahui apakah variabel Inventory Turnover, Sales Growth dan liquidity berpengaruh secara parsial terhadap profitabilitas.

\begin{tabular}{|l|l|c|c|c|c|c|}
\hline \multicolumn{2}{|c|}{} & \multicolumn{2}{|c|}{$\begin{array}{c}\text { Unstandardized } \\
\text { Coefficients }\end{array}$} & $\begin{array}{c}\text { Standardized } \\
\text { Coefficients }\end{array}$ & \multirow{2}{*}{$\mathrm{t}$} & \multirow{2}{*}{ Sig. } \\
\cline { 2 - 5 } & $\mathrm{B}$ & Std. Error & Beta & & \\
\hline \multirow{2}{*}{1} & (Const) & -.019 & .014 & & -1.343 & .185 \\
\cline { 2 - 7 } & $\mathrm{X} 1$ & .032 & .013 & .307 & 2.486 & .016 \\
\cline { 2 - 7 } $\mathrm{X} 2$ & .042 & .008 & .587 & 5.047 & .000 \\
\hline \multirow{2}{*}{$\mathrm{X} 2$} & -.013 & .006 & -.245 & -2.087 & .041 \\
\hline
\end{tabular}

Hasil uji t variabel Inventory Turnover menghasilkan nilai signifikan sebesar $0,01<$ 0,05. Hal ini menunjukkan Inventory Turnover memiliki pengaruh secara parsial terhadap profitabilitas. Hasil uji $\mathrm{t}$ variabel Sales growth menghasilkan nilai signifikan sebesar $0,00<0,05$. Hal ini menunjukkan Sales growth memiliki pengaruh secara parsial terhadap profitabilitas. . Hasil uji $\mathrm{t}$ variabel Liquidity menghasilkan nilai signifikan sebesar $0,04<0,05$. Hal ini menunjukkan Liquidity memiliki pengaruh secara parsial terhadap profitabilitas.

\section{Uji Statistik F}

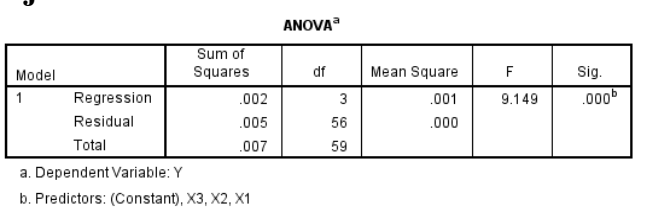

Berdasarkan hasil Uji $\mathrm{F}$, nilai $\mathrm{F}$ hitung sebesar 9,149 dengan nilai sig $0,00<0,05$ menunjukkan bahwa variabel Inventory Turnover, Sales Growth dan Liquidity berpengaruh secara simultan terhadap profitabilitas.

\section{Uji koefisien Determinasi}

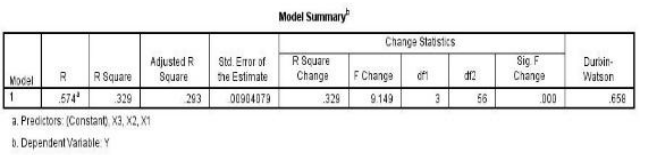

Koefisien determinasi ditujukan untuk mengetahui seberapa besar kemampuan model dalam menerangkan variabel independen terhadap variabel dependen. Dimana nilai $\left(\mathrm{R}^{2}\right)$ sebesar $29,3 \%$ pengaruh dependen dijelaskan oleh variasi independen.

\section{Kesimpulan}

1. Dari hasil penelitian yang telah dilakukan bahwa Inventory Turnover berpengaruh secara parsial terhadap 
profitabilitas dimana ketika persediaan naik maka total laba akan naik.

2. Dari hasil penelitian yang telah dilakukan bahwa Sales growth Berpengaruh secara parsial terhadap profitabilitas dimana ketika penjualan naik maka laba naik

3. Dari hasil penelitian yang telah dilakukan bahwa Liquidity, berpengaruh secara parsial terhadap profitabilitas dimana ketika aktiva lancar naik maka laba naik

4. Dari hasil penelitian yang telah dilakukan bahwa Inventory Turnover, Sales Growth dan Liquidity berpengaruh secara simultan terhadap profitabilitas

\section{UCAPAN TERIMA KASIH}

1. Kepada Tuhan YME yang telah memberikan hikmat kepintaran dan juga kesehatan sehingga kami dapat menyelesaikan nya dengan keadaan sehat dan juga penuh hikmat

2. Ibu Keumala Hayati, S.E., M.Si selaku Dosen Pembimbing I atas bimbingan dan arahan Ibu dalam proses penyelesaian jurnal skripsi ini.

3. Bapak Antonius KAP Simbolon S.Pd., M.Pd selaku Dosen Pembimbing II atas bimbingan dan arahan Bapak dalam proses penyelesaian jurnal skripsi ini.

4. Seluruh Staff bagian Akademik Fakultas Ekonomi Universitas Prima Indonesia yang telah membantu peneliti dalam hal informasi dan administrasi selama peneliti berada di Universitas Prima Indonesia.

5. Seluruh Bapak/Ibu Dosen yang telah memberikan pengarahan dan ilmunya selama peneliti menimba ilmu di Fakultas Ekonomi Universitas Prima Indonesia.

6. Kepada orang tua kami telah memberikan dukungan, arahan dan motivasi serta memberikan doa selama proses penyusunan berlangsung hingga selesai tepat pada waktunya.

\section{DAFTAR PUSTAKA}

Arif, syaiful, dkk. 2015. Pengaruh Perputaran Modal Kerja Leverage Dan Pertumbuhan Penjualan Terhadap Profitabilitas Pada Perusahaan Makanan Dan Minuman Yang Terdaftar di Bursa Efek Indonesia. Jurnal. Fakultas Ilmu Administrasi Universitas Brawijaya (UB) Malang. Vol 27 No 1.

Ghozali, Imam. 2013. Aplikasi Analisis Multivariate dengan Program IBM SPPS. Cetakan Kedelapan. Semarang : Badan Penerbit Universitas Diponegoro.

Hantono, T S Hwee. 2017. Pengaruh Likuiditas, ukuran perusahaan, leverage terhadap profitabilitas dengan coporate social responsibility sebagai variabel intervening pada perusahaan consumer good yang terdaftar di Bursa Efek Indonesia. Jurnal fakultas ekonomi departemen akuntansi . Universitas Prima Indonesia. Volume 4 no 3

Hayati, Keumala. 2016. Pengaruh Rasio Aktifitas, Likuiditas, Dan Solvabilitas Terhadap Profitabilitas Pada Perusahaan Makanan Dan Minuman Yang Terdaftar Di Bursa Efek Indonesia Periode 2010-2013. Jurnal. Fakultas Ekonomi Universitas Prima Indonesia. Volume VI no 1

Kasmir,. 2012. Analisis Laporan Keuangan. Jakarta : Rajawali Pers.

Murhadi, R Warner. 2013. Analisi Laporan Keuangan Proyeksi Dan Valuasi Saham. Jakarta: Salemba Empat.

Raharjaputra, Hendra S, 2011. Manajemen Keuangan Dan Akuntansi untuk Eksekutif Perusahaan.Cetakan Pertama. Jakrarta: Salemba Empat.

Sutrisno. 2013. Manajemen Keuangan. Yogyakarta : Ekonisia 